\title{
Comparative study of flexural strength of temporary restorative resin according to surface polishing and fabrication methods
}

\author{
Jae-Hun Lim, Jae-In Lee* \\ Department of Prosthodontics, College of Dentistry, Wonkwang University, Iksan, Republic of Korea
}

Purpose: The purpose of this study is to investigate the effect of surface polishing and fabrication method on the flexural strength of temporary restorative resin. Materials and Methods: Each of four fabrication methods was used to make 30 temporary restorative resin specimens and the specimens were divided into two groups depending on whether they were polished by mechanical polishing. Specimens were stored in $37^{\circ} \mathrm{C}$ thermostat for 24 hours. Flexural strength was measured using a universal testing machine (UTM). The data obtained through the experiment were analyzed with Two-way ANOVA, Tukey's HSD test and Paired t-test. Results: CAD/CAM milling group showed the highest flexural strength regardless of surface polishing. In decreasing order, the flexural strength of the other fabrication method group was as follows SLA 3D printing, DLP 3D printing, and Conventional method group. Conclusion: Surface polishing did not affect flexural strength of the temporary restorative resin $(P>0.05)$. However, there were statistically significant differences in flexural strength depending on fabrication method $(P<0.05)$. (J Dent Rehabil Appl Sci 2021;37(1):16-22)

Key words: flexural strength; temporary restorative resin; fabrication method; surface polishing

\begin{abstract}
서론
고정성 보철물 제작을 위한 과정 중 임시 고정성 수복 물의 제작은 중요한 부분을 차지한다. 임시 고정성 수복 물은 삭제된 치아의 저작 및 심미기능의 일부를 회복해 주며, 지대치의 정출 및 이동방지, 그리고 치은의 건강유 지를 통한 치은퇴축을 예방하고, 생활치의 경우에는 치 수 진정 및 보호역할도 하게 된다. ${ }^{1}$ 최근에는 임플란트의 발달과 함께 임시 고정성 수복물 사용의 중요성이 더욱 커지고 있다. ${ }^{2}$

치주치료, 근관치료, 턱관절장애의 치료, 임플란트 수 복기간 동안의 결과를 평가하기 위해 장기간 임시 고정 성 수복물이 사용되어질 때 굽힘강도는 매우 중요하다. ${ }^{3}$ 또한 long span bridge의 수복시에나 환자가 이갈이나 이

*Correspondence to: Jae-In Lee

Professor, Department of Prosthodontics, College of Dentistry, Wonkwang University, 77 Doonsan-ro, Seo-gu, Daejeon, 35233, Republic of Korea Tel: +82-42-366-1100, Fax: +82-42-366-1115, E-mail: cash78@empas.com Received: February 1, 2021/Last Revision: February 28, 2021/Accepted: March 3, 2021
\end{abstract}

악물기 같은 비기능적 습관이 있을 때 특히 굽힘강도는 중요한 특성이다. ${ }^{4}$

기존의 전통적인 제작방법은 임시 고정성 보철물의 제 작은 보통 자가중합형 레진, 특히 PMMA 계열의 자가 중합형 레진으로 주로 제작되었고, 술자의 숙련도에 민 감하다는 단점이 있었지만, ${ }^{5}$ Computer aided design/ Computer aided manufacturing (CAD/CAM) 시스 템의 발달과 함께 제작방법이 디지털화되고 다양해졌 다. ${ }^{6} \mathrm{CAD} / \mathrm{CAM}$ 시스템을 이용한 방법에는 절삭가공 (subtractive manufacturing) 방법과 적층가공(additive manufacturing) 방법으로 나뉘게 된다. ${ }^{7}$

절삭가공 방법은 현재 임시 고정성 수복물 제작 외에 도 치과분야의 여러 가지 부분에서 사용되어 지는 CAD/ $\mathrm{CAM}$ 시스템이다. ${ }^{8}$ 하지만 절삭가공 방법으로 임시 고 
정성 수복물을 제작하게 될 경우, 소음이 크며, bur를 이 용하여 절삭하기 때문에 복잡한 형태의 제작은 어려움이 있고, 절삭하고 남은 블록의 경우 재사용이 불가능하여 재료 낭비가 심하다는 단점이 있다.

그에 반해 적층가공 방법인 3D 프린터는 가루 또는 액 상의 형태로 분사하거나, 원하는 부위에만 레이저 혹은 프로젝터 등으로 조사하여 결과물을 만들기 때문에 절 삭가공과 비교하여, 재료낭비가 적고 미세부 재현성이 우수하다는 장점이 있다. ${ }^{9}$ 현재는 photopolymer jetting (Poly jet), multi jetting modeling (MJM), streolithography apparatus (SLA), digital light processing (DLP) 등 많은 $3 \mathrm{D}$ 프린터 중 SLA와 DLP 타입이 치과용 레진 제 작에 주로 사용되고 있다. ${ }^{10}$

이렇듯 다양해진 제작방법으로 제작된 임시 고정성 수 복물은 환자의 구강 내에 시적하여 교합조정 등의 마무 리 과정을 거치고 최종적으로는 표면연마 과정 후에 합 착을 시행하게 된다. 적합한 마무리와 연마는 수복물의 심미와 내구성을 위하여 매우 중요한 단계이며, 표면연 마는 레진의 기계적 성질 향상에 영향을 끼칠 수 있다고 보고되었다. ${ }^{11}$ 그러나, 현재까지는 주로 전통적인 제작방 법으로 제작한 임시 수복용 레진의 강도 비교에 관한 연 구에 국한되어 진행되어 졌고, 다양한 제작방법으로 제 작된 임시 고정성 레진에 대한 강도 비교 및 표면연마과 정을 거친 후 강도 변화에 관하여 복합적으로 분석하는 연구가 필요하다.

따라서 본 연구에서는 기존의 전통적인 방법으로 제작 된 임시 수복용 레진과 절삭가공법으로 제작된 임시 수 복용 레진, 적층가공법(SLA 3D 프린터, DLP 3D 프린 터)으로 제작된 임시 수복용 레진의 굽힘강도 비교 및 각 각의 레진에 표면연마를 가하였을 때 변화한 굽힘강도를 비교하고자 한다.

\section{연구 재료 및 방법}

임시 수복용 레진 시편은 기계적 연마 여부 및 제작방 법을 달리하여 제작하였다. 4 가지의 제작방법으로 각각 30 개의 시편을 제작하였고, 그 중 15 개씩의 시편을 기계 적 연마로 표면연마처리하였으며, 기계적 연마를 시행 하지 않은 군은 NP, 기계적 연마를 시행한 군은 $\mathrm{P}$ 로 표 시하여 총 8 그룹으로 나누었다(Table 1). 시편은 치과 용 복합레진의 국제규격(ISO 10477:2004)가 제시하는 방법에 따라 $25 \times 2 \times 2 \mathrm{~mm}$ (길이 $\times$ 높이 $\times$ 폭) 크기의 빔(beam) 형태의 시편을 제작하였다. 첫 번째 제작방법 $(\mathrm{CON})$ 은 전통적인 방법(conventional method)으로 기 존의 Polymethyl methacrylate (PMMA)계열의 자가중 합형 레진(Tokuso curefast, Tokuyama Dental Corp., Toyko, Japan)을 제조사가 지시한 비율 및 시간대로 핸 드믹싱하여 특수 제작한 stainless steel mold에 전입한 후 기포 함입을 막기 위해 유리판으로 압접하여 실제 임 상에서 직접법으로 제작하는 것과 동일하게 대기 중에 서 중합하여 제작하였다(Fig. 1). 두 번째 제작방법(MIL)

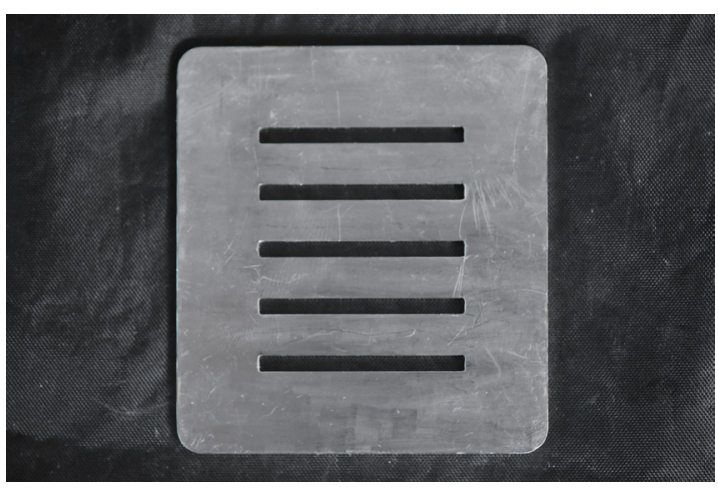

Fig. 1. Stainless steel mold mold to fabricate temporary restorative resin specimens by conventional method (45 $\times 50 \times 2 \mathrm{~mm}$ )

Table 1. Information about methods and materials used in this study

\begin{tabular}{|c|c|c|c|c|c|}
\hline Group & Method & Polishing & Product & Manufacturer & Material \\
\hline $\begin{array}{l}\text { CON-NP } \\
\text { CON-P }\end{array}$ & Conventional method & $\begin{array}{l}\text { No } \\
\text { Yes }\end{array}$ & - & - & Tokuso curefast \\
\hline $\begin{array}{l}\text { MIL-NP } \\
\text { MIL- P }\end{array}$ & CAM/CAM milling & $\begin{array}{l}\text { No } \\
\text { Yes }\end{array}$ & Arum 5x-200 & Doowon ID & Yamahachi PMMA disk \\
\hline $\begin{array}{l}\text { SLA-NP } \\
\text { SLA-P }\end{array}$ & SLA 3D Printing & $\begin{array}{l}\text { No } \\
\text { Yes }\end{array}$ & Zenith U & Dentis & ZMD-1000B temporary \\
\hline $\begin{array}{l}\text { DLP-NP } \\
\text { DLP-P }\end{array}$ & DLP 3D printing & $\begin{array}{l}\text { No } \\
\text { Yes }\end{array}$ & Asiga Max UV & Asiga & Detax Freeprint temp \\
\hline
\end{tabular}


은 절삭가공 방법으로 CAD software (Exocad DentalCAD, Exocad GmbH, Darmstadt, Germany)로 디자 인하여 milling machine (ARUM 5X-200, DOOWON ID, Daejeon, Korea)을 이용해 PMMA block (Yamahachi PMMA disk, YAMAHACHI DENTAL MFG., CO., Gamagori, Japan)을 절삭하였고, 세 번째 제작방법(SLA) 은 적층가공 방법 중 SLA 3D 프린터(Zenith U, DENTIS, Daegu, Korea)로 광경화성 액상수지(ZMD-1000B TEMPORARY, DENTIS, Daegu, Korea)를 적층하여 제작하였다. 그리고 네 번째 제작방법(DLP)은 DLP 3D 프린터(Asiga MAX UV, ASIGA, Sydney, Australia)로 광경화성 액상수지(Detax Freeprint temp, Detax, Ettlingen, Germany)를 적층하여 제작하였다.

표면연마는 4 가지의 제작방법으로 제작된 30 개의 시 편 중 15 개의 시편에만 시행되었다. 표면연마를 위해 먼저 저속 핸드피스에 carbide denture bur (079CE045, NTI-kahla GMBH, Kahla, Germany) (15초, $20,000 \mathrm{RPM}$ )를 끼워 표면을 마무리하였으며, 그 후 silicone polisher (P0657, NTI) (15초, 10,000RPM)를 저속 핸드피스에 끼워 연마하였고, lathe wheel (15초, 3,000RPM)에 pumice (Fine grit CL-125, Whip Mix, Louisville, USA)를 묻혀 연마를 마무리하였다.

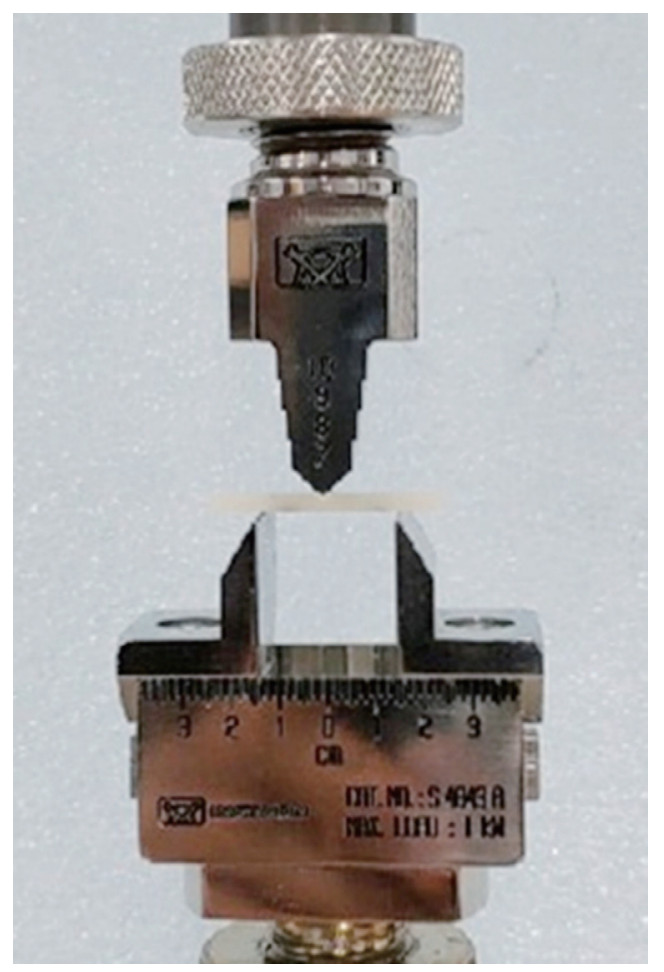

Fig. 2. Flexural strength test.
모든 시편은 $37^{\circ} \mathrm{C}$ 항온기에 24 시간 보관 후 universal testing machine (Instron 5848, Instron, Canton, USA) 을 이용하여 3점 굽힘 시험을 시행하였다. 하중속도는 2 $\mathrm{mm} / \mathrm{min}$ 으로 두 지지대 사이의 거리는 $15 \mathrm{~mm}$ 로 설정하 였고(Fig. 2), 굽힘강도(MPa)는 ISO 10477에 따라 다음 과 같은 공식으로 계산하였다.

$$
\begin{aligned}
& \sigma=3 \mathrm{Fl} / 2 \mathrm{bh}^{2} \\
& \mathrm{~F}(\mathrm{~N}): \text { 최대 하중 } \\
& \text { l }(\mathrm{mm}) \text { : 지지대 사이의 거리 }(15 \mathrm{~mm}) \\
& \mathrm{b}(\mathrm{mm}) \text { : 시편의 너비 } \\
& \mathrm{h}(\mathrm{mm}) \text { : 시편의 두께 }
\end{aligned}
$$

통계방법은 SPSS version 25 (SPSS Inc., Chicago, USA) 프로그램을 사용하여 표면연마 여부 및 제작방법 에 따른 임시 수복용 레진의 굽힘강도 차이를 평가하기 위해 이원분산분석(two-way ANOVA)를 시행하였으며, 이원분산분석의 사후검정법으로는 Tukey's HSD test를 채택하였고 신뢰 수준은 $95 \%(P=0.05)$ 에서 통계적 유 의성을 검증하였다. 또한 각각의 제작방법으로 제작된 임시 수복용 레진의 표면연마 여부에 따른 굽힘강도 차 이는 Paired t-test로 추가 검정하였다.

\section{결과}

측정결과, 절삭가공법으로 제작 후 연마를 시행한 MIL 군(MIL-P)에서 $188.13 \pm 14.80 \mathrm{MPa}$ 로 가장 높은 굽힘강도를 나타냈고, 전통적인 방법으로 제작 후 연마 를 시행하지 않은 $\mathrm{CON}$ 군(CON-NP)에서 $67.50 \pm 6.71$ $\mathrm{MPa}$ 로 가장 낮은 굽힘강도를 나타냈다 (Table 2, Fig. 3). 임시 수복용 레진의 굽힘강도는 표면연마와 제작방법 사이에 유의할만한 상호 작용이 없는 것으로 나타났다 $(P$ $>0.05)$ (Table 3).

또한 표면연마에 의한 굽힘강도도 통계학적으로 유의 한 차이는 없었다 $(P>0.05)$.

Table 2. Flexural strength (Mean \pm SD) of temporary restorative resin specimens $(\mathrm{n}=15)$

\begin{tabular}{ccc}
\hline Group & $\begin{array}{c}\text { Non-surface polishing } \\
(\mathrm{NP})\end{array}$ & $\begin{array}{c}\text { Surface polishing } \\
(\mathrm{P})\end{array}$ \\
\hline CON & $67.50 \pm 6.71$ & $71.60 \pm 5.92$ \\
MIL & $181.51 \pm 9.96$ & $188.13 \pm 14.80$ \\
SLA & $175.55 \pm 12.36$ & $177.53 \pm 9.62$ \\
DLP & $168.44 \pm 25.51$ & $172.49 \pm 13.54$ \\
\hline
\end{tabular}




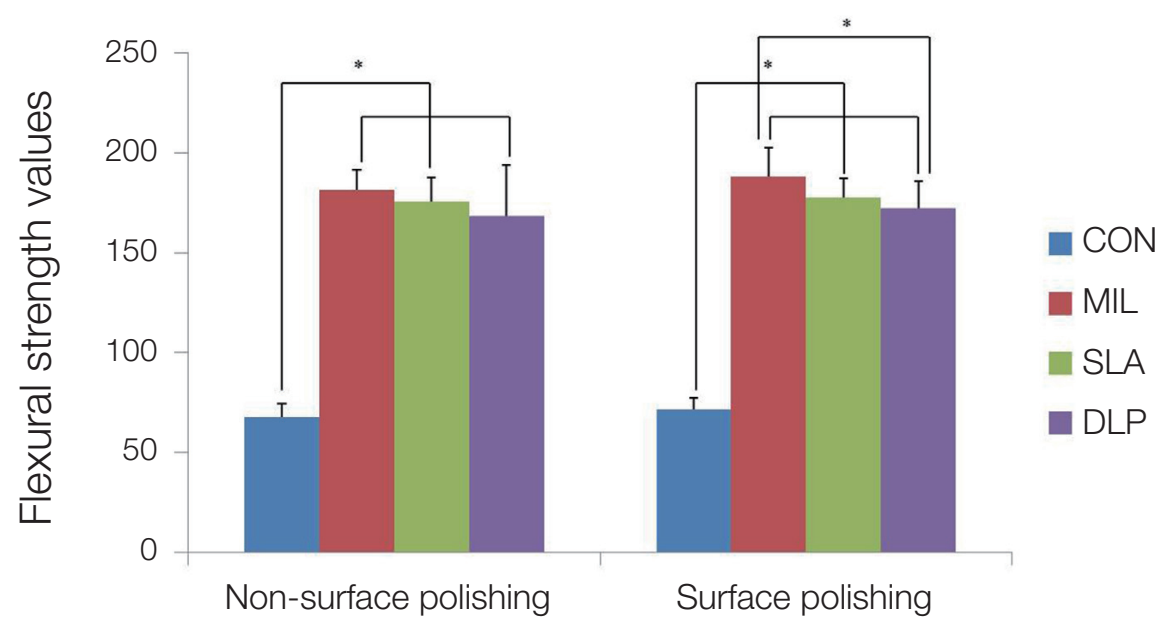

Fig. 3. Flexural strength values (Mean + SD) of temporary restorative resin specimen. CON, Conventional method; MIL, CAD/CAM milling; SLA, SLA 3D printing; DLP, DLP 3D printing. * : Significant difference, $P<0.05$.

Table 3. Two-way ANOVA with surface polishing and fabrication method

\begin{tabular}{lcccc}
\hline \multicolumn{1}{c}{ Factor } & Df & Mean square & F-value & $P$-value \\
\hline Surface polishing & 1 & 525.887 & 2.847 & .094 \\
Fabrication method & 3 & 88077.626 & 476.837 & $.000^{*}$ \\
Surface polishing $\times$ Fabrication method & 3 & 27.058 & 0.146 & .932 \\
\hline
\end{tabular}

* : Significant difference, $P<0.05$.

제작방법에 따른 굽힘강도는 통계학적으로 유의한 차 이가 나타났고 $(P<0.05), \mathrm{CON}$ 군(CON-NP, CON$\mathrm{P})$ 은 나머지 모든 군과 통계학적으로 유의한 차이를 보 였고 $(P<0.05)$, MIL 군(MIL-NP, MIL-P)과 DLP 군 (DLP-NP, DLP-P) 사이에서도 통계학적으로 유의한 차 이를 보였고 $(P<0.05)$, 나머지 군 사이에서는 통계학적 으로 유의한 차이를 나타내지 않았다 $(P>0.05)$.

\section{고찰}

자가중합형 레진을 이용하여 전통적인 방법으로 임시 고정성 수복물을 제작할 때는 제조사의 지시대로 제작하 였으며, 과도한 liquid의 양이 레진 중합 시 물리적 성질 을 감소시킨다는 선행연구의 결과를 바탕으로 진행하였 다. ${ }^{12,13}$

또한 Donovan 등의 연구에 의하면 대기 중에서 중합 시킬 때보다 pressure vessle을 이용하여 압력 하에서 중 합시킨 레진이 통계학적으로 유의하게 더 높은 굽힘강도
를 보인다고 하였지만, ${ }^{14,15}$ 본 실험에서는 실제 임상 상황 에서 술자가 제작하는 상황을 가정하여 대기 중에서 중 합시켜 제작하였다.

표면연마와 제작방법 간에는 상호작용 효과는 없으며, 표면연마는 임시 수복용 레진의 굽힘강도에 영향을 미치 지 않는 것으로 나타났고, 제작방법이 굽힘강도에 영향 을 미치는 주요 인자임을 알 수 있었다. 또한 연마 여부와 관계없이 전통적인 방법으로 제작한 $\mathrm{CON}$ 군 $(\mathrm{CNP}, \mathrm{CP})$ 이 현저히 낮은 굽힘강도를 나타냈고, $\mathrm{CAD} / \mathrm{CAM}$ milling으로 제작한 $\mathrm{MIL}$ 군 $(\mathrm{MNP}, \mathrm{MP})$ 이 가장 높은 굽힘강 도를 나타냈다.

$\mathrm{CON}$ 군 $(\mathrm{CNP}, \mathrm{CP})$ 과 $\mathrm{MIL}$ 군 $(\mathrm{MNP}, \mathrm{MP})$ 은 둘 다 PMMA 레진임에도 불구하고 굽힘강도에서 많은 차이를 나타냈다. 이것은 CAD/CAM milling으로 제작한 MIL 군(MNP, MP)에서 사용하는 PMMA 블록은 제작 시 압 축하여 제작하기 때문에 내부에 기포 발생이 감소하여 강도가 증가할 뿐만 아니라, ${ }^{16}$ 미리 중합하여 제작되기 때문에 보다 더 높은 중합도를 보여서 더 적은 잔류 단량 
체가 나오게 된다. 이에 반해 전통적인 제작방법으로 제 작한 PMMA 레진은 술자가 직접 핸드믹싱하여 제작하 기 때문에 PMMA 블록과 다르게 균일하지 않으며 술자 의 미숙함으로 인해 liquid와 powder 혼합 시 공기 함입 으로 인해 내부에 기포가 더 많이 발생하여 강도가 감소 하게 된다. ${ }^{17}$ Reeponmaha 등에 의하면 레진의 내부 기포 및 다공성의 증가는 강도의 감소를 야기시키며, ${ }^{17}$ Ayman 등에 의하면 높은 잔류 단량체 함량은 레진의 기계적 강 도에 유해한 영향을 끼친다고 하였다. ${ }^{18}$ 따라서 위와 같 은 이유들로 인해 $\mathrm{MIL}$ 군과 $\mathrm{CON}$ 군 사이에 굽힘강도의 차이가 나타나는 것으로 생각된다.

전통적인 방법으로 제작한 $\mathrm{CON}$ 군 $(\mathrm{CNP}, \mathrm{CP})$ 과 적 층가공법으로 제작한 $\mathrm{DLP}$ 군(DNP, DP), SLA 군(SNP, $\mathrm{SP})$ 사이에서도 통계적으로 유의한 차이가 나타났고, 그 이유는 사용된 레진 종류의 차이로 인한 것으로 생각 되며, 전통적인 방법으로 제작한 자가중합형 레진이 적 층가공법으로 제작한 광중합형 레진보다 낮은 물리적, 기계적 성질을 나타냈다는 선행연구 결과와도 일치한 다. ${ }^{19,20}$

SLA 3D 프린터와 DLP 3D 프린터로 제작한 임시 수 복용 레진 사이에서는 통계학적으로는 유의하지 않지만, SLA 3D 프린터로 제작한 SLA 군(SNP, SP)의 굽힘강도 가 $\mathrm{DLP} 3 \mathrm{D}$ 프린터로 제작한 $\mathrm{DLP}$ 군(DNP, DP)보다 높게 나타났는데, 그 이유는 프린팅 방식의 차이에서 찾 아볼 수 있다. SLA 3D 프린터는 광경화성 액상 수지에 $\mathrm{UV}$ 레이저를 조사하여 적층하는 방식으로 점 단위로 레 이저를 조사하여 경화시킨다. 이에 반해 DLP 타입의 3D 프린터는 광경화성 액상수지에 Digital light projector를 조사하여 면 단위로 조사하게 된다. 따라서 SLA 3D 프 린터로 제작한 레진은 DLP 3D 프린터로 제작한 레진에 비해 전반적으로 완전한 중합이 이루어져 더 적은 양의 잔류 단량체가 남게 되고, 이로 인해 더 높은 굽힘강도를 나타내는 것으로 생각된다. ${ }^{21,22}$

레진의 표면연마 시행 후 잔류 단량체의 감소로 인해 굽힘강도가 증가한다고 제시한 Goncalves 등의 연구 결 과와는 달리, ${ }^{11}$ 본 연구에서는 모든 제작방법에서 표면연 마에 따른 굽힘강도가 통계학적으로 유의한 차이를 나 타내지 않았다. 그 이유는 표면연마에 의한 임시 수복용 레진의 굽힘강도 증가효과는 미비하여 통계학적으로 유 의한 차이를 나타내지는 못한 것으로 생각된다.

임시 고정성 수복물의 경우 ISO 10477:2004가 제시한 기준에 따르면, 굽힘강도가 $50 \mathrm{MPa}$ 이상이어야 한다. 본
연구에서 시험된 모든 그룹의 시편에서 평균 굽힘강도가 $50 \mathrm{MPa}$ 이상으로 나타나 임상적으로 사용 가능한 수준 임을 알 수 있었다.

그렇지만 본 연구는 실제 구강 내에서 시행한 연구가 아니기 때문에 한계가 있으며, 구강 내 상황을 더 정확히 재현하기 위해서는 thermocycling 등 다양한 조건을 추 가하여 연구가 필요할 것으로 생각된다.

\section{결론}

4가지 제작 방법(Conventional method, CAD/CAM milling, SLA 3D printing, DLP 3D printing)으로 제작 한 임시 수복용 레진 시편의 표면연마 여부를 달리하여 각각의 굽힘강도를 측정 비교한 결과 다음과 같은 결론 을 얻었다.

1. 임시 수복용 레진의 굽힘강도에서 표면연마와 제작 방법 사이에는 유의할만한 상호작용 효과가 없었다.

2. 제작방법에 따른 임시 수복용 레진의 굽힘강도는 유 의할만한 차이가 있었다.

3. 표면연마 여부에 따른 임시 수복용 레진의 굽힘강도 는 유의할만한 차이가 없었다.

4. CAD/CAM milling으로 제작한 MIL 군(MNP, MP) 은 가장 높은 굽힘강도를 나타냈으며, Conventional method로 제작한 $\mathrm{CON}$ 군 $(\mathrm{CNP}, \mathrm{CP})$ 은 나머지 모 든 군보다 통계학적으로 유의하게 낮은 굽힘강도를 보였다.

\section{Acknowledgements}

This paper was supported by Wonkwang University in 2021.

\section{ORCID}

Jae-Hun Lim https://orcid.org/0000-0001-9453-2136

Jae-In Lee https://orcid.org/0000-0002-3026-0693

\section{References}

1. Koumjian JH, Holmes JB. Marginal accuracy of provisional restorative materials. J Prosthet Dent 1990;63:639-42. 
2. Burns DR, Beck DA, Nelson SK. A review of selected dental literature on contemporary provisional fixed prosthodontic treatment: report of the Committee on Research in Fixed Prosthodontics of the Academy of Fixed Prosthodontics. J Prosthet Dent 2003;90:474-97.

3. Haselton DR, Diaz-Arnold AM, Vargas MA. Flexural Strength of Provisional Crown and Fixed Partial Denture Resins. J Prosthet Dent 2002;87:225-8.

4. Ireland MF, Dixon DL, Breeding LC, Ramp MH. In Vitro Mechanical Property Comparison of Four Resins Used for Fabrication of Provisional Fixed Restorations. J Prosthet Dent 1998;80:158-62.

5. Diaz-Arnold AM, Dunne JT, Jones AH. Microhardness of provisional fixed prosthodontics materials. J Prosthet Dent 1999;82:525-8.

6. Park JY, Jeong ID, Lee JJ, Bae SY, Kim JH, Kim WC. In vitro assessment of the marginal and internal fits of interim implant restorations fabricated with different methods. J Prosthet Dent 2016;116:536-42.

7. Kim KB, Kim JH, Kim WC, Kim JH. Three-dimensional evaluation of gaps associated with fixed dental prostheses fabricated with new technologies. J Prosthet Dent 2014;112:1432-6.

8. Park SM, Kim SK, Park JM, Kim KH, Jeon Y'T, Koak JY. Flexural strength of various kinds of the resin bridges fabricated with $3 \mathrm{D}$ printing. J Dent Rehabil Appl Sci 2017;33:260-8.

9. Karaokutan I, Sayin G, Kara O. In vitro study of fracture strength of provisional crown materials. J Adv Prosthodont 2015;7:27-31.

10. Cho W'T, Choi JW. Comparison analysis of fracture load and flexural strength of provisional restorative resins fabricated by different methods. J Korean Acad Prosthodont 2019;57:225-31.

11. Gonçalves TS, de Menezes LM, Silva LEA. Residual monomer of autopolymerized acrylic resin according to different manipulation and polishing methods. An in situ evaluation. Angle Orthod 2008;78:722-7.

12. Palitsch A, Hannig M, Ferger P, Balkenhol M. Bonding of acrylic denture teeth to MMA/PMMA and light-curing denture base materials: the role of conditioning liquids. J Dent 2012;40:210-21.

13. Wang X, Huyang G, Palagummi SV, Liu X, Skrtic D, Beauchamp C, Bowen R, Sun J. High performance dental resin composites with hydrolytically stable monomers. Dent Mater 2018;34:228-37.

14. Donovan TE, Hurst RG, Campagni WV. Physical properties of acrylic resin polymerized by four different techniques. J Prosthet Dent 1985;54:522-4.

15. Chee WW, Donovan TE, Daftary F, Siu TM. The effect of vacuum-mixed autopolymerizing acrylic resins on porosity and transverse strength. J Prosthet Dent 1988;60:517-9.

16. Yao J, Li J, Wang Y, Huang H. Comparison of the flexural strength and marginal accuracy of traditional and CAD/CAM interim materials before and after thermal cycling. J Prosthet Dent 2014;112:64957.

17. Reeponmaha T, Angwaravong O, Angwarawong T. Comparison of fracture strength after thermomechanical aging between provisional crowns made with CAD/CAM and conventional method. J Adv Prosthodont 2020;12:218-24.

18. Ayman AD. The residual monomer content and mechanical properties of CAD/CAM resins used in the fabrication of complete dentures as compared to heat cured resins. Electron Physician 2017;9:4766-72.

19. Matsumura H, Leinfelder KF. Three-body wear of four types of light-activated composite resin veneering materials. Quintessence Int 1994;25:425-30.

20. Peutzfeldt A. Resin composites in dentistry: the monomer systems. Eur J Oral Sci 1997;105:97-116.

21. Lee S. Prospect for 3D Printing Technology in Medical, Dental, and Pediatric Dental Field. J Korean Acad Pediatr Dent 2016;43:93-108.

22. Dikova T, Dzhendov DA, Ivanov D, Bliznakova K. Dimensional accuracy and surface roughness of polymeric dental bridges produced by different 3D printing processes. Arch Mater Sci Eng 2018;94:6575. 


\section{표면연마와 제작방법에 따른 임시 수복용 레진의 굽힘강도에 관한 비교 연구}

임재훈 대학원생, 이재인* 교수

원광대학교 치과대학 치과보철학교실

목적: 표면연마와 제작방법이 임시 수복용 레진의 굽힘강도에 미치는 영향을 분석하고자 한다.

연구 재료 및 방법: 4 가지 제작방법을 이용하여 각각 30 개의 임시 수복용 레진 시편을 제작하였고, 기계적 연마로 표면연 마를 시행한 그룹과 연마를 시행하지 않은 2 개의 그룹으로 나누었다. 시편은 $37^{\circ} \mathrm{C}$ 항온기에 24시간 보관 후 만능시험 기(Universal testing machine)을 이용하여 3점 굽힘강도를 측정하였다. 통계분석은 Two-way ANOVA와 Tukey's HSD test, Paired t-test를 이용하여 분석하였다.

결과: 표면연마 여부와 관계없이 CAD/CAM milling으로 제작한 시편이 가장 높은 굽힘강도를 나타냈고, SLA 3D printing, DLP 3D printing, Conventional method 순으로 높은 굽힘강도를 나타냈다.

결론: 표면연마는 임시 수복용 레진의 굽힘강도에 유의한 영향을 끼치지 못했지만 $(P>0.05)$, 제작방법에 의해서는 굽힘 강도의 유의한 차이가 나타났다 $(P<0.05)$.

(구강회복응용과학지 2021;37(1):16-22)

주요어: 굽힘강도; 임시 수복용 레진; 제작방법; 표면연마

*교신저자: 이재인

(35233) 대전광역시 서구 둔산로 77 원광대학교 대전치과병원 치과보철과

Tel: 042-366-1100 | Fax: 042-366-1115 | E-mail: cash78@empas.com

접수일: 2021년 2월 1일 | 수정일: 2021년 2월 28일 | 채택일: 2021년 3월 3일 